\title{
Article \\ Influence Mechanism of a Bridge Wind Barrier on the Stability of a Van-Body Truck under Crosswind
}

\author{
Zhiqun Yuan ${ }^{1,2, *}$, Dandan Xia ${ }^{3,4}$, Xiaobo Lin $^{3}, \operatorname{Li~Lin}^{3,5, *}$, Yufeng Liu ${ }^{1}$ and Yuehan $\mathrm{Li}^{1}$ \\ 1 School of Mechanical and Automotive Engineering, Xiamen University of Technology, Xiamen 361024, China; \\ 17858788125@163.com (Y.L.); xiaozhua0101@163.com (Y.L.) \\ 2 Fujian Collaborative Innovation Center for R\&D of Coach and Special Vehicle, Xiamen 361024, China \\ 3 Fujian Provincial Key Laboratory of Wind Disaster and Wind Engineering, Xiamen 361024, China; \\ xia229@uregina.ca (D.X.); 210510010@fzu.edu.cn (X.L.) \\ 4 Industrial Systems Engineering, University of Regina, Regina, SK S4S 0A2, Canada \\ 5 School of Civil Engineering and Architecture, Xiamen University of Technology, Xiamen 361024, China

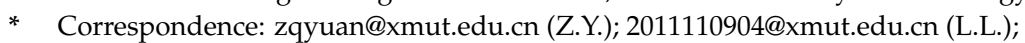 \\ Tel.: +86-137-7992-9841 (Z.Y.); +86-159-6038-8901 (L.L.)
}

check for

updates

Citation: Yuan, Z.; Xia, D.; Lin, X.; Lin, L.; Liu, Y.; Li, Y. Influence Mechanism of a Bridge Wind Barrier on the Stability of a Van-Body Truck under Crosswind. Atmosphere 2022, 13, 360. https://doi.org/10.3390/ atmos 13020360

Academic Editors: Qiusheng Li, Junyi He and Bin Lu

Received: 19 January 2022

Accepted: 3 February 2022

Published: 21 February 2022

Publisher's Note: MDPI stays neutral with regard to jurisdictional claims in published maps and institutional affiliations.

Copyright: (c) 2022 by the authors. Licensee MDPI, Basel, Switzerland. This article is an open access article distributed under the terms and conditions of the Creative Commons Attribution (CC BY) license (https:/ / creativecommons.org/licenses/by/ $4.0 /)$.

\begin{abstract}
Understanding the crosswind stability of cars under strong wind loads and research on wind resistance methods is important for improving the safety performance of wind-induced driving on bridges. Taking van-body trucks as the research object, numerical calculation methods and wind tunnel test methods are used to conduct the wind-induced driving safety analyses of van trucks on a cross-sea bridge. The influence of the structural parameters of the barrier-type wind barrier on the aerodynamic characteristics and straight-line driving stability of the trucks on the bridge is studied and analyzed quantitatively. The results show that the decrease in the porosity of the wind barrier can effectively reduce the average wind speed of the bridge deck, and increasing the height of the wind barrier can effectively reduce the wind speed and increase the occlusion height of the bridge deck. The lateral acceleration, yaw rate, and lateral displacement of trucks decrease with the decrease in the porosity of the wind barrier and decrease with the increase in the height of the wind barrier. The research conclusions can not only provide data support for wind-induced driving safety analysis and the wind-resistant design of bridges but also provide a new method to balance the requirements of bridge wind-induced driving safety and bridge wind-induced structure safety.
\end{abstract}

Keywords: van-body truck; sea-cross bridge; bridge wind barrier; wind-induced driving safety; crosswind stability

\section{Introduction}

The van-body truck is one of the typical models driven on bridges. It has a high center of gravity and a large side windward surface and is susceptible to strong winds. Many traffic accidents caused by crosswinds have been reported, and wind-induced driving safety ability has received extensive attention from relevant scholars at home and abroad [1-3]. As investigated by researchers, strong winds will change the flow pattern around cars and have an important influence on the aerodynamic force and aerodynamic torque of cars $[4,5]$, which is the main cause of safety accidents on bridges. Therefore, executing crosswind stability analysis of van-body trucks and research on wind resistance methods have important social significance for improving efficiency and traffic safety of cross-sea bridges.

To reduce the occurrence of traffic accidents on the bridge during windy weather, setting up bridge wind barriers along bridge decks is one of the crucial means to avoid wind-induced traffic safety accidents [6]. At present, long-span bridges domestically and overseas, such as the Hong Kong-Zhuhai-Macao Bridge, the Hangzhou Bay Bridge, the Ningbo Xiangshan Port Bridge, the Millau Viaduct in France, and the Second Severn 
Bridge in the United Kingdom have all installed wind barriers on the bridge deck to ensure the safety of vehicles passing on the bridge. The setting of the wind barrier can change the characteristics of the wind environment on the bridge surface, reduce the wind speed, and thereby reduce the aerodynamic force and aerodynamic torque of the vehicle on the bridge, and improve the driving safety of the vehicle [7]. The influence of wind barriers is related to many factors. First, the bridge deck wind environment and automobile aerodynamic characteristics are obviously affected by the type of wind barrier [8]. Striptype wind barriers have been widely used in long-span bridges worldwide. Chen et al. obtained the aerodynamic coefficient of trucks with three kinds of wind barriers by wind tunnel tests [9], and the influence of wind barriers on vehicle safety was analyzed using a theoretical analysis method. Second, the height and porosity of the wind barrier are the key parameters that affect its wind resistance performance $[10,11]$, and a better combination of height and porosity can improve the wind-induced driving safety of vehicles. Wang et al. determined the aerodynamic performance of vehicles running under wind barriers using dynamic grid technology [12], and it was found that stepped wind barriers with 50\% porosity had the best wind reduction effect. Moreover, the location of the wind barrier is another critical parameter that affects the wind resistance performance. Research shows that setting the wind barrier only on the leeward side of the bridge cannot effectively improve the aerodynamic performance of the car [13]. Finally, the influence rules of wind barriers on different lanes on the bridge deck or different vehicle types are different and need to be analyzed in detail for specific problems [14]. Zhang et al. found that the aerodynamic characteristics of vehicles are related to the shape of the vehicle body and the parameters of the wind barrier [15], and wind barriers provide adequate protection for windward vehicles. In summary, reasonable wind barrier structure parameters and setting methods will positively affect the aerodynamic characteristics of vehicles on bridges. However, few studies have focused on the influence of wind barriers on vehicle driving stability, and studies have mainly been carried out on the analysis of the impact of wind barriers on the aerodynamic parameters of the bridge deck and the stationary vehicle aerodynamic performance, and interactive aerodynamic effects between the car-bridge-crosswind caused by the vehicle movement and the impact of bridge wind barriers on vehicle driving stability are ignored, but, the study by Xiang et al. showed that the movement of the vehicle causes changes in aerodynamic force and aerodynamic torque [16]. It is impossible to accurately predict the impact pattern of bridge wind barriers on vehicle wind-induced driving safety performance on bridges and may underestimate the significance of bridge wind barriers for wind-induced safety of vehicles. The increase in the aerodynamic load of the wind barrier caused by too small wind barrier porosity and too high of a wind barrier height will have an important influence on the wind resistance of the bridge itself.

It is widely known that reducing the porosity and increasing the height of the wind barrier affects the aerodynamic shape of the bridge and greatly increases the aerodynamic load of the bridge, which is very detrimental to the overall structural safety of the bridge [17]. After the porosity is reduced from $60 \%$ to $40 \%$, the aerodynamic load of the wind barrier will increase by $20 \%$. If the height of the wind barrier increases from $1 \mathrm{~m}$ to $3 \mathrm{~m}$, the aerodynamic load increases two times. Consequently, the balance between the bridge's wind-induced traffic safety and the wind-induced structural safety is an important technical problem to be solved and it is necessary to design a quantitative research method of wind barrier parameters on driving safety performance. In addition, it is necessary to systematically study its influence mechanism systematically to avoid the negative impact caused by improper settings which may not only increase the investment cost of bridge construction but also change the bridge's actual aerodynamic performance thereby reducing the wind resistance performance of the bridge structure [10]. In this paper, the computational fluid dynamics method and the wind tunnel test method are used to analyze the influence of striper-type wind barrier structure parameters on the aerodynamic performance of trucks. Based on this, the multiple-body dynamics method is applied to quantitatively analyze and evaluate the regular influence of wind barrier structure parameters on the straight-line 
driving stability of van-body trucks. The corresponding research results can provide more scientific reference data and theoretical support for bridge wind resistance design and driving safety evaluation which may have important social significance and economic benefits.

\section{Aerodynamic Truck Model and Validation}

In this paper, a 1:1 box-type bridge model in established in 3D modeling software. This research mainly focuses on the influence of wind barrier structure parameters on the crosswind stability of vehicles; therefore, the bridge's aerodynamic interference is ignored, and a three-lane single-width bridge is used for numerical simulation. In the calculation, the van drives in the middle lane of the bridge, and the three-dimensional geometric model of the van and the bridge are shown in Figure 1. Strip-type wind barriers are installed on both sides of the bridge deck to calculate and analyze the impact of the porosity and height changes on wind-induced driving safety. The porosity includes three levels of 40\%,50\%, and $60 \%$, and the height contains three levels of $1 \mathrm{~m}, 2 \mathrm{~m}$, and $3 \mathrm{~m}$ (with a porosity of 50\%). The parameters of wind barrier setting include the common parameters of existing bridge wind barriers and the geometric model of the wind barrier scheme is shown in Figure 2.

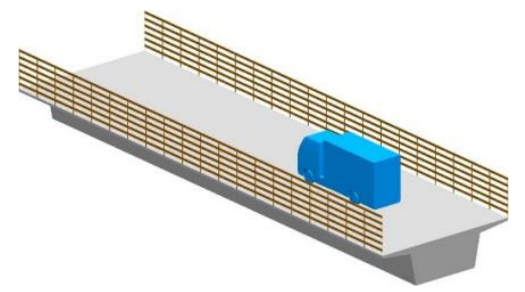

(a)

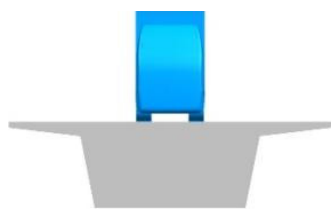

(b)

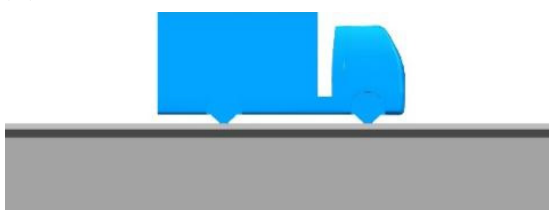

(c)

Figure 1. Geometric model of the truck on the bridge ((a) Axonometric view of bridge; (b) front view of the bridge; (c) side view of the bridge).

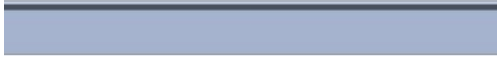

(a)

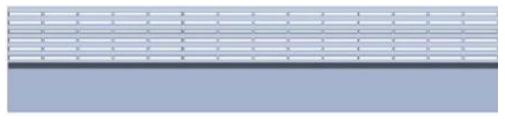

(b)

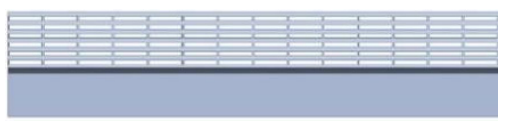

(c)

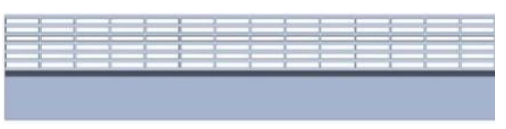

(d)

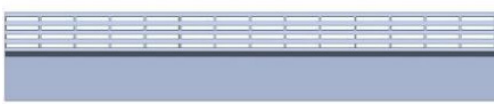

(e)

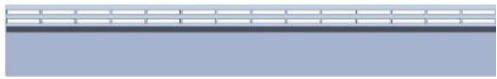

(f)

Figure 2. Geometric models of the bridge wind barrier ((a) Bare bridge; (b) Scheme 1 of the wind barrier: the porosity is $40 \%$, and the height is $3 \mathrm{~m}$; (c) Scheme $2-1$ of the wind barrier: the porosity is $50 \%$, and the height is $3 \mathrm{~m}$; (d) Scheme 3 of wind barrier: the porosity is $60 \%$, and the height is $3 \mathrm{~m}$; (e) Scheme 2-2 of wind barrier: the porosity is 50\%, and the height is $2 \mathrm{~m}$; (f) Scheme 2-3 of the wind barrier: the porosity is $50 \%$, and the height is $1 \mathrm{~m}$ ). 
The aerodynamic analysis model of the van-body truck traveling on the bridge is established by using the overlapping grid method of STAR-CCM+, as shown in Figure 3. The calculation domain includes the background region and the overset region. The overset region with a width of $3 \mathrm{~L} \times 3 \mathrm{~B} \times 2 \mathrm{H}$ is positioned in the background region at a distance of $6 \mathrm{~B}$ from the inlet of the side wind, $13 \mathrm{~B}$ from the outlet of the side wind, and $4 \mathrm{H}$ from the up wall, L is the length of the truck, B is the width of the truck and $\mathrm{H}$ is the height of the truck. The truck is positioned in the overset region at a distance of $0.5 \mathrm{~L}$ from the front, 1.5 L from the back, $\mathrm{H}$ from the top, and B from the side. The movement speed $\mathrm{v}$ of the overset region is set as $80 \mathrm{~km} / \mathrm{h}$, and the crosswind inlet wind speed vs. of the background region is $25 \mathrm{~m} / \mathrm{s}$. The whole process of driving from the road to the bridge deck at a speed of $80 \mathrm{~km} / \mathrm{h}$ under a side wind of $25 \mathrm{~m} / \mathrm{s}$ is simulated.

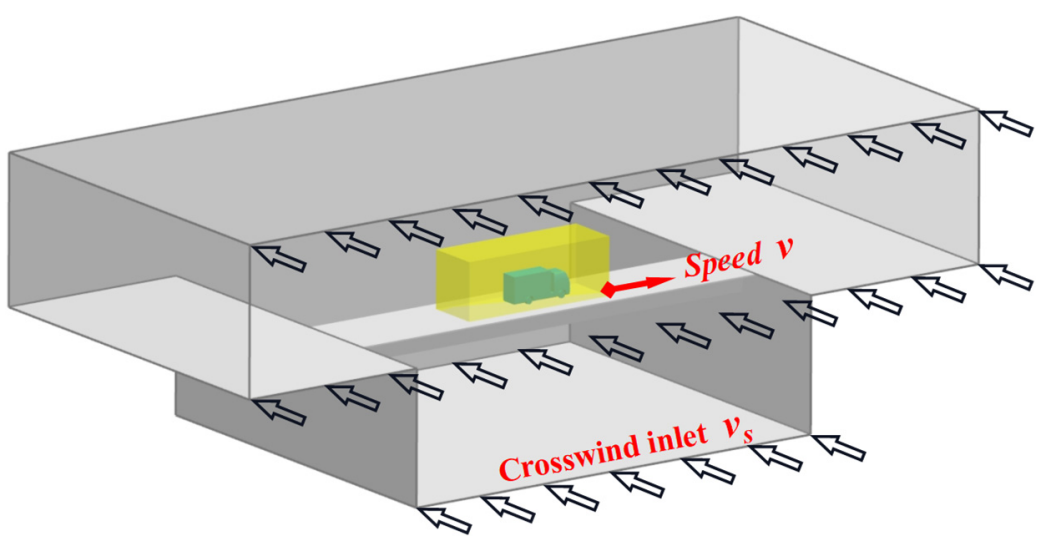

Figure 3. Analysis method for a vehicle on the bridge: the black arrows represent the direction of the crosswind and the direction is perpendicular to the crosswind inlet surface.

For the setting of the model, the background region is encrypted with multilayer volume grids, and the wind barrier and the car body surface are set as multilayer grids with boundary layers to accurately capture the flow pattern distribution of the wind barrier and the car body surface. Fifteen layers of elements are generated from the truck's surface, and the initial height is $0.1 \mathrm{~mm}$, with a growth rate of 1.1, keeping the $y+$ value within an acceptable value in this study. The grid size of the background region is $512 \mathrm{~mm}$, and the grid size of the overset region is $64 \mathrm{~mm}$. The background region is provided with three layers of encryption area, the size of the first layer of encryption area is $256 \mathrm{~mm}$, the size of the second layer of encryption area is $128 \mathrm{~mm}$, and the size of the third layer of encryption area is $64 \mathrm{~mm}$. The overall grid of the calculation domain for bare bridge case is about 30 million and that for wind barrier case is 45 million. It is proven that the calculation results are independent of the number of grids by setting different grid sizes. The calculation model of driving is shown in Figure 4.

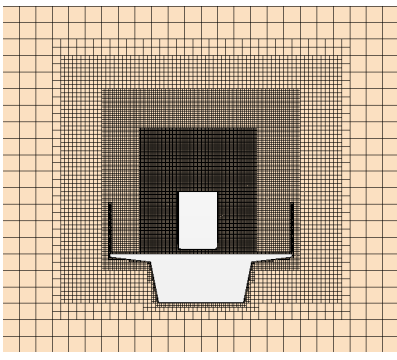

(a)

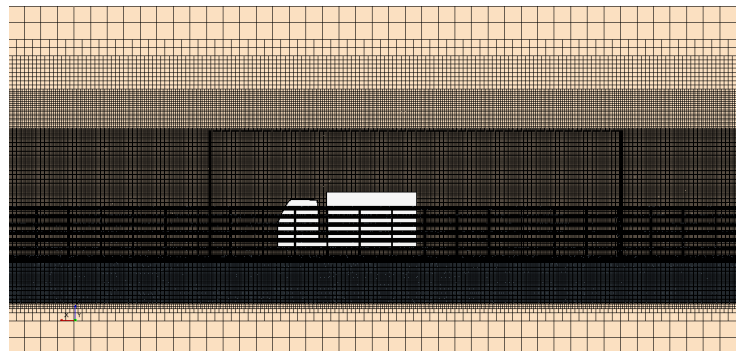

(b)

Figure 4. The mesh rendering of a vehicle on the bridge ((a) Front view of the domain; (b) side view of the domain). 
The leeward surface, left and right boundary surfaces, and the upper boundary surface of the primary domain are set as pressure outlets with relative atmospheric pressure 0 , and the others are set as wall boundaries. The calculation is solved by the large eddy simulation method and the subgrid scale model, which has a higher calculation accuracy comparing than the Renault time average method, which has been widely used in automobile external flow fields and dynamic grid calculations $[18,19]$.

The wind speed reduction coefficient and relative wind velocity are used to verify the accuracy of the numerical calculation model. The wind speed reduction coefficient is defined as formula (1). $z_{r}$ is the height range of the bridge wind profile, and the value is $45 \mathrm{~cm} . \mathrm{u}(\mathrm{z})$ is the transverse wind speed value at the height $z$ on the carriageway centerline, and $u_{0}$ is the wind speed of incoming flow. The wind tunnel test is described in Section 4. The figures show the comparison between the numerical simulation results and wind tunnel test results under bare bridge conditions. As shown in Figures 5 and 6, the results obtained by the two methods in each lane are relatively similar, especially at the measuring points with a higher height from the bridge deck. However, when the height is lower than the front, there is a large deviation between the wind tunnel test and the simulation results at each measuring point. One of the reasons for the error comes from the calculation model, such as the grid and the turbulence model. Conversely, the large velocity gradient near the ground will lead to jitter of the anemometer, which will cause error in the position of the measuring point. The wind tunnel test of the wind speed reduction coefficient is close to the numerical simulation results, which shows that the numerical simulation method is feasible.

$$
\mathrm{r}=\sqrt{\frac{1}{\mathrm{z}_{\mathrm{r}}} \int_{0}^{\mathrm{z}_{\mathrm{r}}}\left(\mathrm{u}(\mathrm{z}) / \mathrm{u}_{0}\right)^{2} \mathrm{dz}}
$$

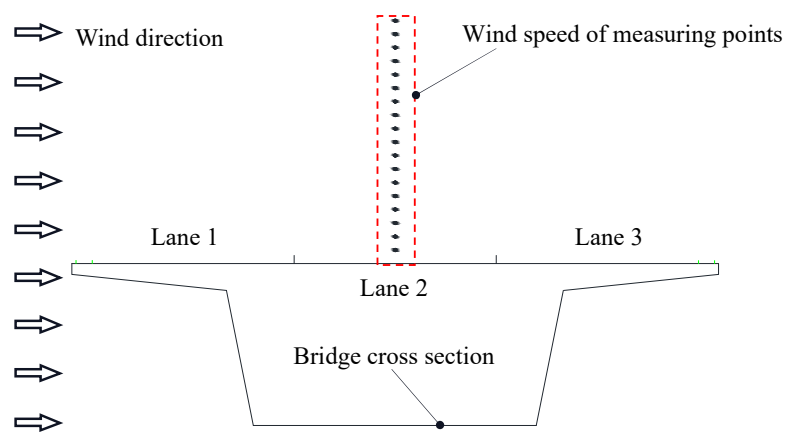

(a)

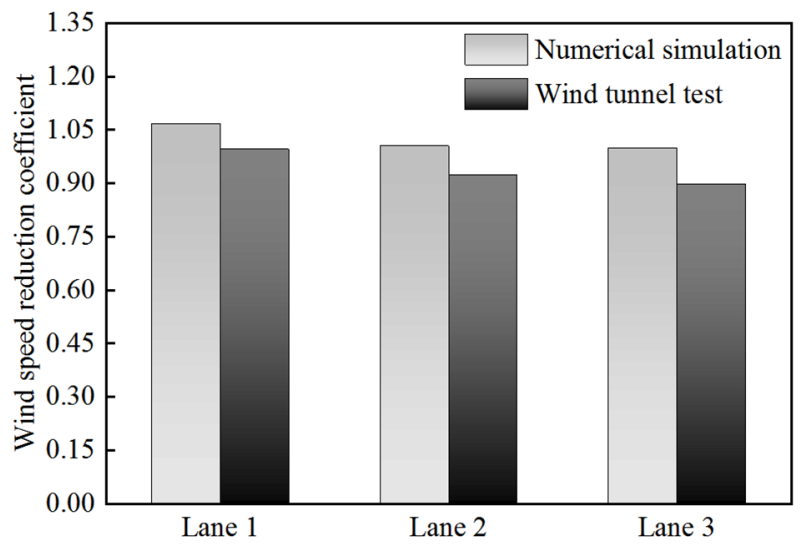

(b)

Figure 5. Wind speed reduction coefficient (r) comparison for the bare bridge condition ((a) Measuring points and lane layout; (b) wind speed reduction coefficient of the bare bridge for different lanes). 


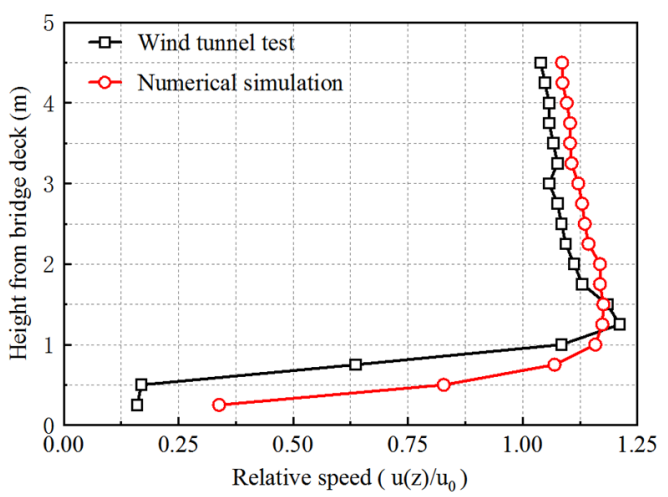

(a)

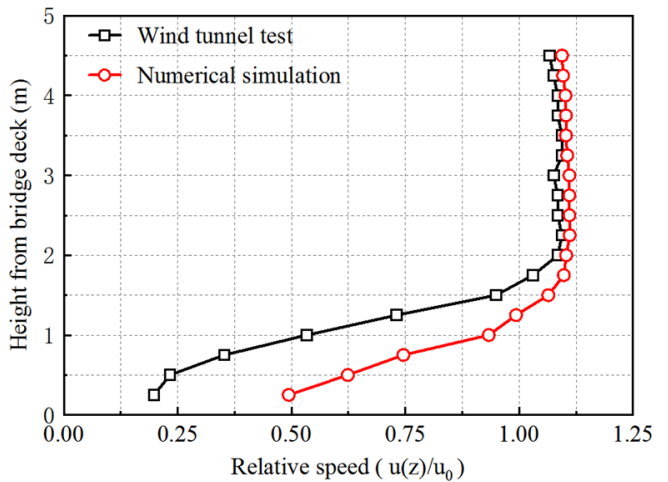

(b)

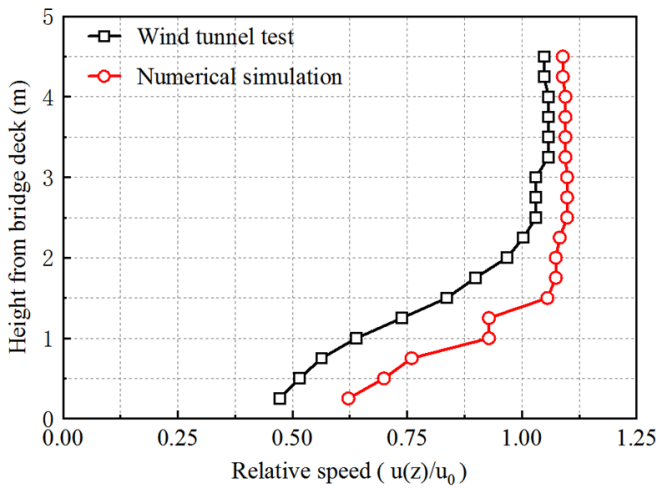

(c)

Figure 6. Comparison of relative wind speed values $\left(\mathrm{u}(\mathrm{z}) / \mathrm{u}_{0}\right)$ for bare bridge conditions (a) Lane 1; (b) Lane 2; (c) Lane 3.

\section{Influence and Analysis of Wind Barriers on the Truck's Aerodynamic Characteristics}

The changes in the wind barrier structure parameters will have different shielding effects on the bridge deck wind field, leading to significant changes in bridge deck wind environmental parameters and vehicle aerodynamic characteristics. The differences in bridge wind barrier schemes can be compared with different structural parameters from the aspects of wind speed distribution on the bridge deck, pressure distribution on van body surfaces, and automotive aerodynamics. Figures 7 and 8 show that with the change of the porosity and height of the wind barrier, the flow patterns around the bridge deck and trucks have changed to different degrees. The cross-section is located in the middle of the bridge span. When there is no wind barrier on the bridge deck, due to the influence of the bridge turbulence, there is an airflow acceleration area near the ground on the windward side of the trucks. The windward side of the truck is simultaneously affected by the airflow acceleration area and the high-speed incoming flow. Maximum speed appears at the transition between the sidewall of the truck and the roof, as well as the bottom of the carriage. After setting up the wind barrier on the bridge deck, the shielding effect significantly reduces the wind speed on the bridge deck and inhibits the high-speed crosswind from directly acting on the windward side of the truck. Therefore, the highest wind speed does not appear at the transition between the sidewall of the truck and the roof and the bottom of the carriage. 


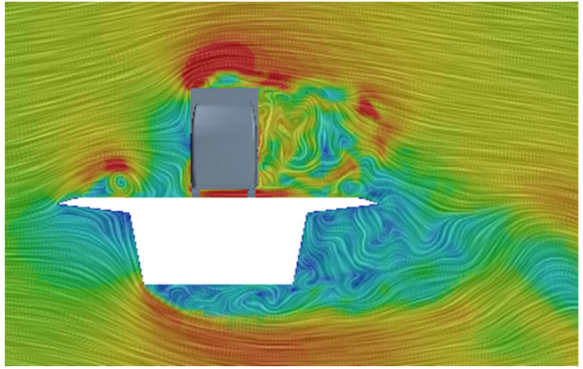

(a)

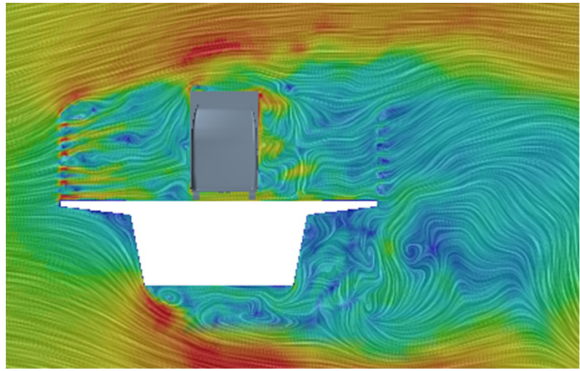

(c)

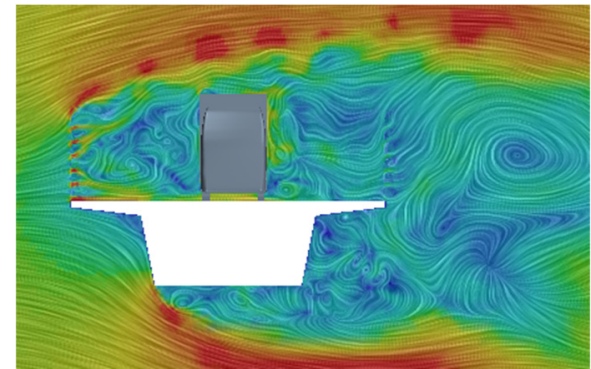

(b)

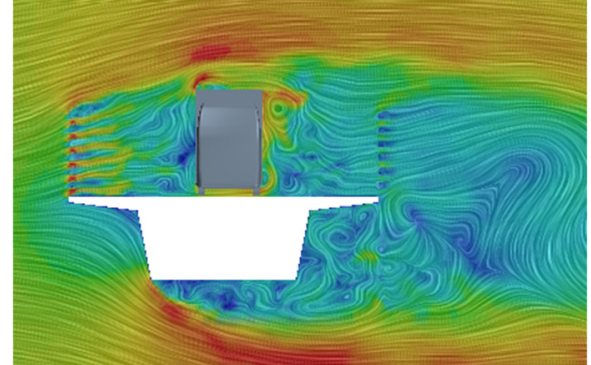

(d)

Velocity $(\mathrm{m} / \mathrm{s})$

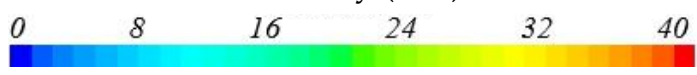

Figure 7. Velocity distribution for different porosity schemes ((a) Bare bridge; (b) Scheme 1; (c) Scheme 2-1; (d) Scheme 3).

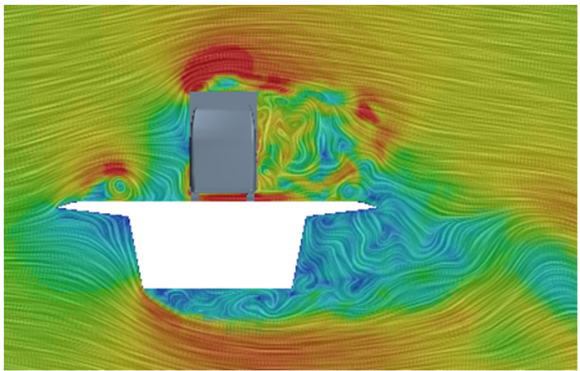

(a)

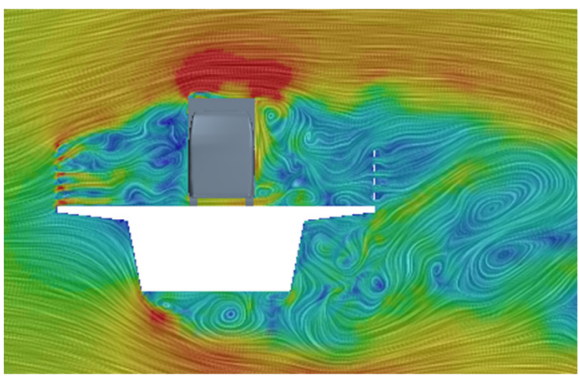

(c)

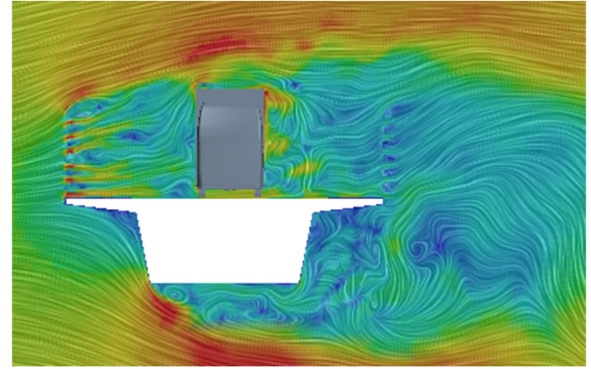

(b)

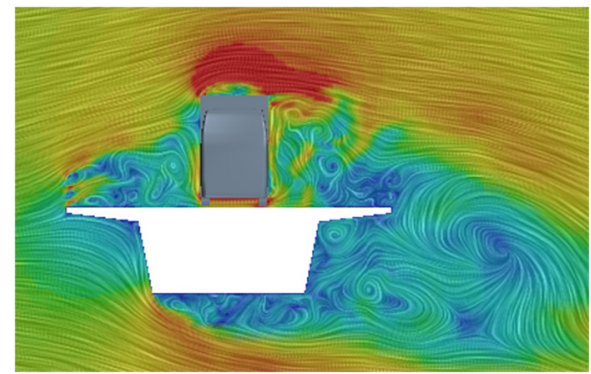

(d)

Velocity $(\mathrm{m} / \mathrm{s})$

$\begin{array}{llllll}0 & 8 & 16 & 24 & 32 & 40\end{array}$

Figure 8. Velocity distribution for different height schemes ((a) Bare bridge; (b) Scheme 2-1; (c) Scheme 2-2; (d) Scheme 2-3). 
When the height of the wind barrier is constant, as the porosity increases, the wind speed on the windward side of the truck gradually increases, and the shielding effect gradually decreases. The strip-type wind barrier will cause local airflow acceleration in the first lane on the windward side zone, which increases as the porosity increases; when the porosity of the wind barrier is constant, the shielding area gradually decreases with decreasing height, and the wind speed of the bridge surface on the windward side of the truck gradually increases. When the height of the wind barrier is small enough, the high-speed airflow generated by the turbulence on the upper part of the wind barrier will directly act on the upper part of the truck.

From Figures 9 and 10, it is apparent that the changes in the porosity and size of the wind barrier have a significant impact on the pressure distribution on the surface of the truck body. When the height of the wind barrier is constant, the increases in porosity will lead to an increase in the maximum positive pressure value and the positive pressure area on the windward side of the truck. The change in the wind speed near the ground causes the pressure distribution at the bottom of the truck to be slightly different. However, there is a significant difference in the negative pressure on the top of the truck, in which the negative absolute value and negative pressure area of the top of the truck in Scheme 3 are significantly larger. When the wind barrier porosity is constant, the reduction in the wind barrier height causes the maximum positive pressure value and the positive pressure area of the truck facing the crosswind to increase. The change in height predominantly affects the pressure distribution on the leeward side. It is apparent that the absolute negative pressure value and negative pressure area of the truck bottom and the leeward side increase with decreasing height.

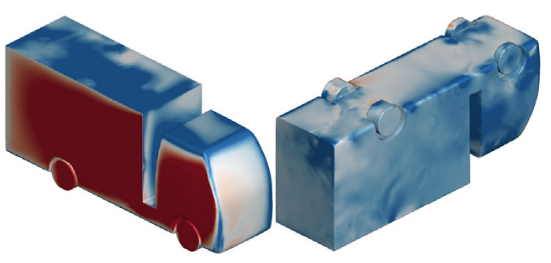

(a)

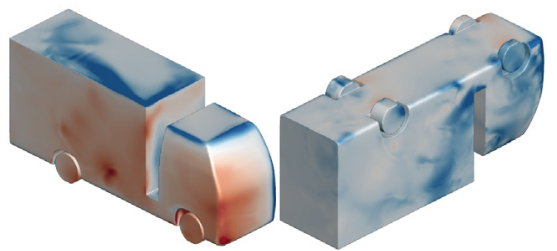

(c)

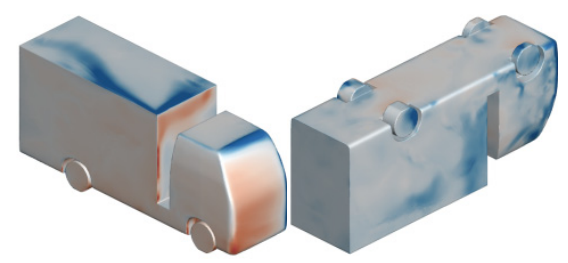

(b)

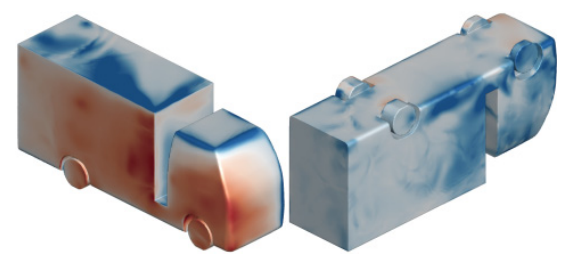

(d)

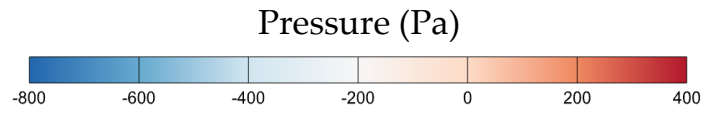

Figure 9. Pressure distribution for different porosity schemes ((a) Bare bridge; (b) Scheme 1; (c) Scheme 2-1; (d) Scheme 3). 


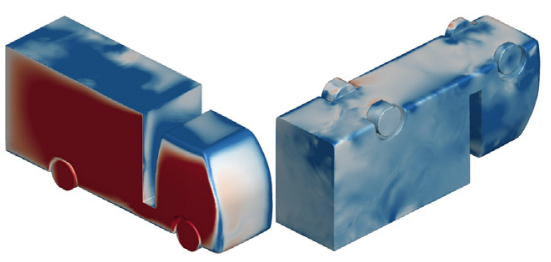

(a)

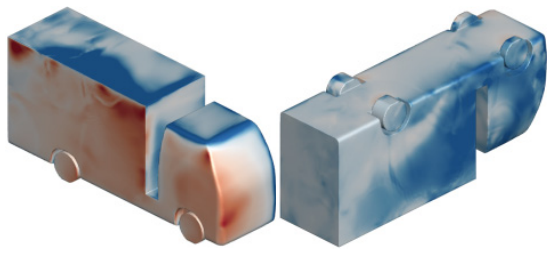

(c)

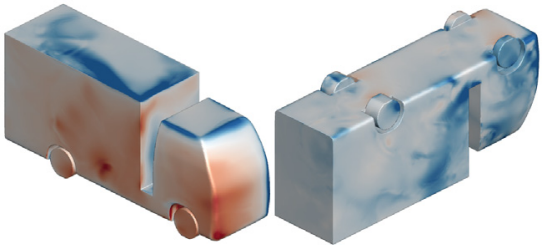

(b)

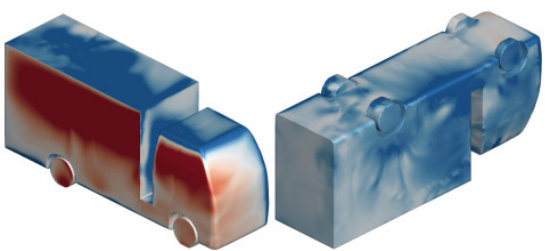

(d)

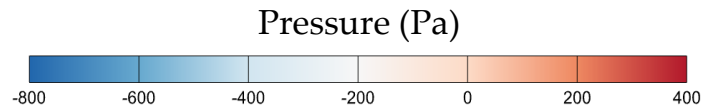

Figure 10. Pressure distribution for different height schemes ((a) Bare bridge; (b) Scheme 2-1; (c) Scheme 2-2; (d) Scheme 2-3).

Variations in the surface pressure distribution of trucks with different wind barriers will result in differences in truck aerodynamics. Aerodynamic side force and aerodynamic lift are the main parameters that affect truck crosswind stability. Figure 11 lists the changing patterns under different wind barrier schemes. The aerodynamic coefficient is evaluated as the average value within $0.5 \mathrm{~s}$ after a steady change. $\mathrm{C}_{\mathrm{S}}$ is the aerodynamic side force coefficient of the truck, and $\mathrm{C}_{\mathrm{L}}$ is the aerodynamic lift force coefficient of the truck, and they are defined as shown in Equations (2) and (3). Where $F_{Y}$ and $F_{Z}$ are the aerodynamic side force of truck, aerodynamic lift force of the truck, respectively; $S$ is the frontal area of the truck; $\rho$ denotes the density and the $\mathrm{v}$ denotes the combined velocity of vehicle velocity and wind velocity. After installing wind barriers on both sides of the bridge, the aerodynamic side force and aerodynamic lift are reduced to different degrees. Nevertheless, the installation has a more significant impact on the aerodynamic side force. The aerodynamic side force increases as the porosity of the wind barrier increases and increases as the height of the wind barrier decreases. The aerodynamic lift does not change significantly with the height of the wind barrier and the porosity. Bridge wind barriers with different structural parameters have different influences on the aerodynamic force of the truck, which in turn have different degrees of impact on the crosswind stability of the truck on the bridge.

$$
\begin{aligned}
& C_{S}=\frac{F_{Y}}{\frac{1}{2} \rho v^{2} S} \\
& C_{L}=\frac{F_{Z}}{\frac{1}{2} \rho v^{2} S}
\end{aligned}
$$




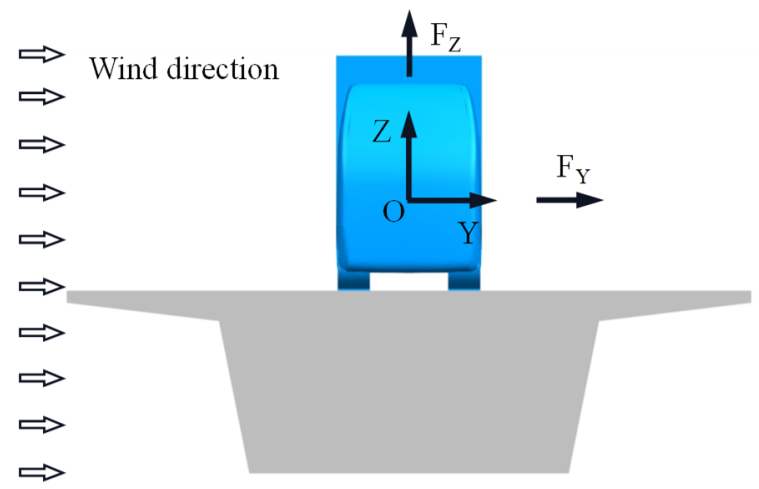

(a)

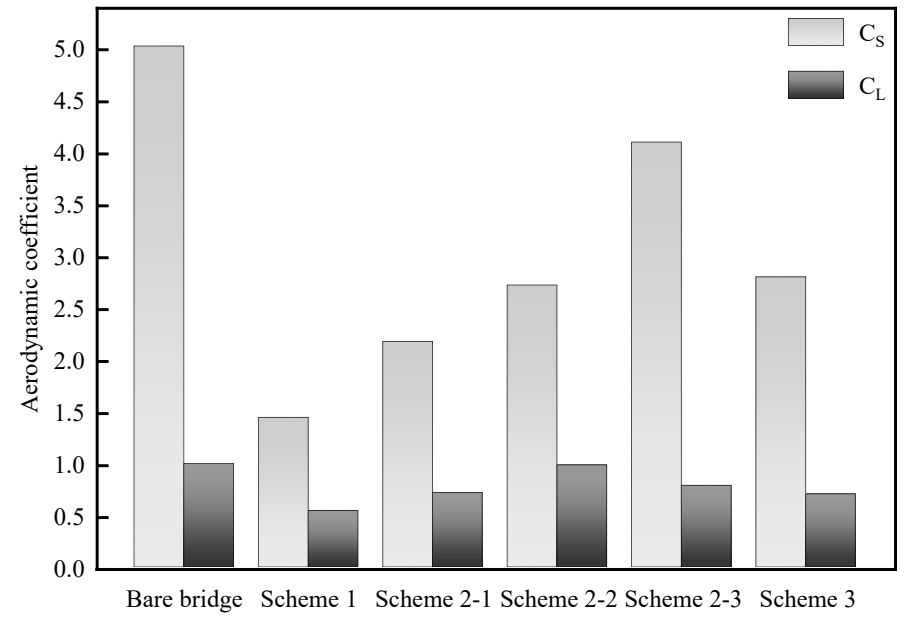

(b)

Figure 11. Aerodynamic force definition and variation law ((a) aerodynamic definition; (b) aerodynamic coefficient of different schemes).

\section{Verification by the Wind Tunnel Test}

The aerodynamic characteristics of the truck and wind resistance verification tests were completed in the low-speed test section of the Wind Tunnel Laboratory of the Xiamen University of Technology. The size of the low-speed test section is $25 \times 6 \times 3.6 \mathrm{~m}$, the shrinkage ratio of 3.36 , the wind speed range of $0.5-30 \mathrm{~m} / \mathrm{s}$, and the turbulence intensity $<0.5 \%$. A 1:10 scaled model of bridge, a van is established. Wind barriers with the same scale and different structural parameters were made for wind tunnel tests. The bridge deck is made of ABS, the internal framework of the bridge is made of stainless steel, and the truck model is made of resin. The model and test site are shown in Figure 12. The blockage ratio of the wind tunnel test model is $4.5 \%$, the test incoming flow velocity is $11.06 \mathrm{~m} / \mathrm{s}$, and the yaw angle of the car-bridge model is $90^{\circ}$. The wind tunnel test includes a speed test and a force test, by the utilization of a cobra three-dimensional pulsating anemometer, and a pneumatic six-component balance, respectively. The aerodynamic sampling frequency is $1000 \mathrm{~Hz}$ and the sampling time is $150 \mathrm{~s}$. The wind speed sampling frequency is $600 \mathrm{~Hz}$ and the sampling time is $60 \mathrm{~s}$. The wind speed of measuring points at the bridge span midpoint were measured, which are within the height range of $0-45 \mathrm{~cm}$ above the carriageway centerline. The first measuring point is $2.5 \mathrm{~cm}$ away from the bridge deck, and a measuring point is set at an interval of $2.5 \mathrm{~cm}$. 


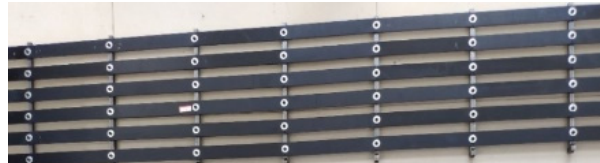

(a)

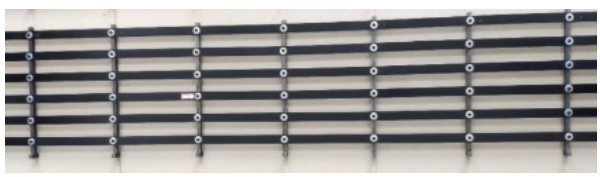

(c)

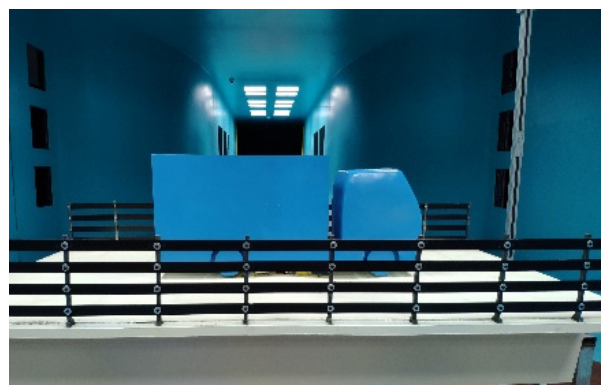

(e)

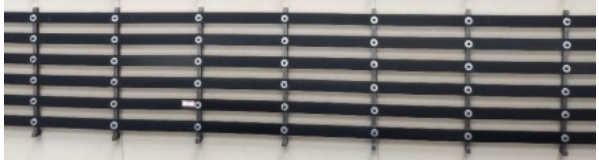

(b)

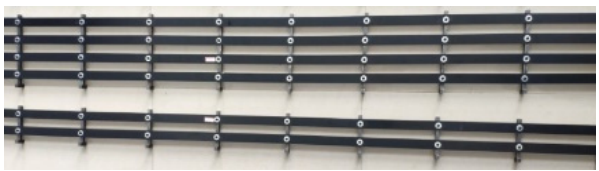

(d)

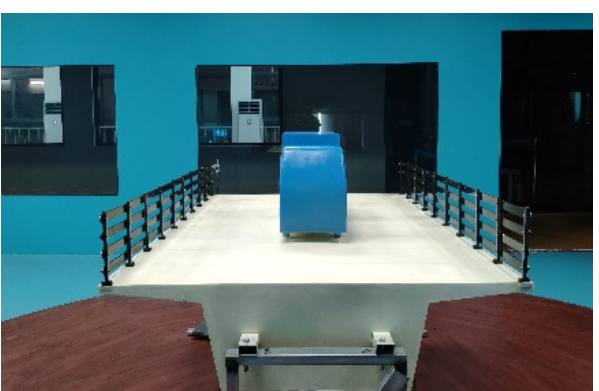

(f)

Figure 12. Wind barrier and wind tunnel test ((a) Scheme 1; (b) Scheme 2-1; (c) Scheme 3; (d) Scheme 2-2 and Scheme 2-3); (e) side view the of wind tunnel test; (f) front view of the wind tunnel test.

As shown in Figures 13 and 14, there are significant differences in the wind speed of bridge decks with different barrier parameters, and the results obtained by the two methods in each lane are relatively similar. The wind speed reduction coefficient is reduced upon the installation of a wind barrier, and it increases with decreasing height and increasing porosity. When the height of the wind barrier is $3 \mathrm{~m}$ and the porosity is $50 \%$, the wind speed within the height of $4.5 \mathrm{~m}$ of bridge deck is less than the wind speed of the incoming flow which can carry out effective protection for all over cars on the bridge. The wind speed profiles on the driving lanes of vans under different wind barrier schemes are shown in Figure 15. Height is a critical parameter for the strip-type barrier that affects the wind resistance performance. For a bare bridge, the wind speed of the bridge deck increases with the increasing ground clearance, and the wind speed below a bridge deck height of $16 \mathrm{~cm}$ is lower than the incoming wind speed. Due to the influence of turbulence on a bridge, the wind speed in the area above a bridge deck height of $16 \mathrm{~cm}$ is higher than the incoming wind speed and reaches the maximum when the distance from the bridge deck is $20 \mathrm{~cm}$. Under wind barrier conditions of different heights, the wind speeds corresponding to the bridge deck area above the height of the strip-type barriers are lower than those of the bare bridge. The wind resistance performance can be improved as the height of the barrier strips increases. The greater the height of the barrier strips, the greater the effective shielding height. However, there is no obvious pattern in the area below the height of the barrier. There are airflow acceleration areas within the height range of $10 \mathrm{~cm}$ near the ground, such as the heights of $20 \mathrm{~cm}$ and $30 \mathrm{~cm}$. The wind speed near the ground is significantly higher than that of the bare bridge, which will result in the lower part of the van wind pressure increasing, which can affect driving safety. 


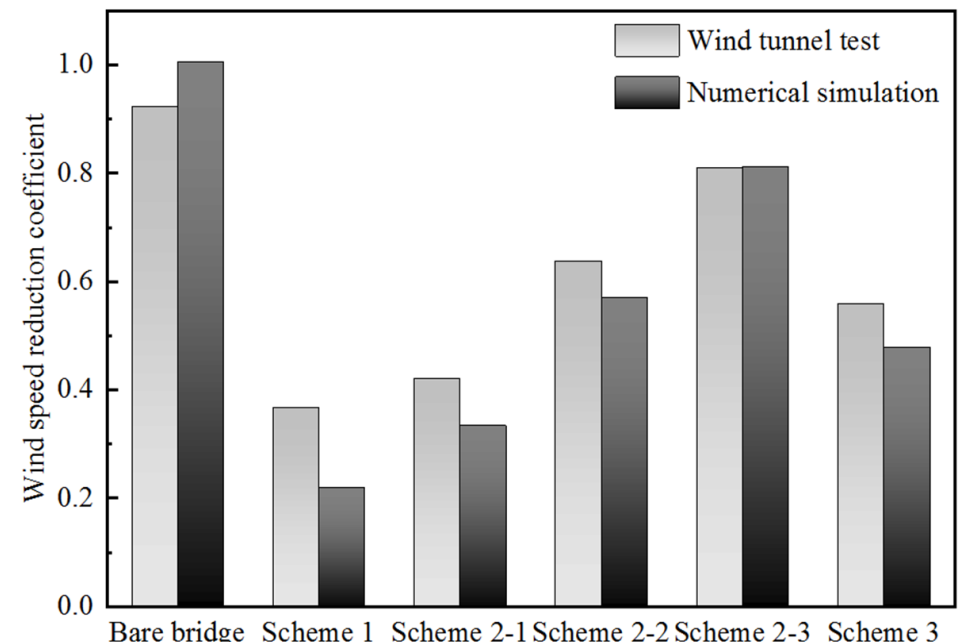

Figure 13. Wind speed reduction coefficient (r) comparison for different wind barriers in lane 2.

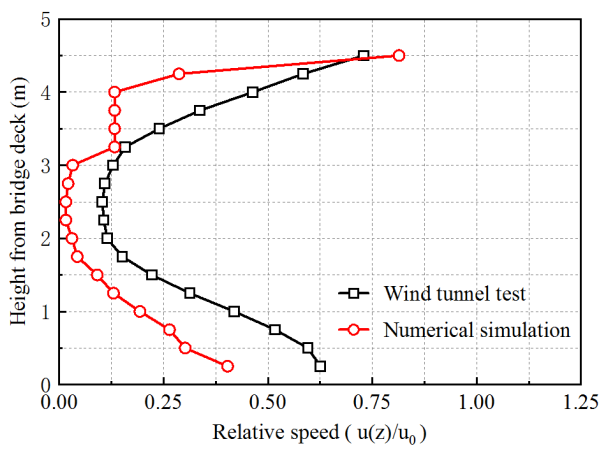

(a)

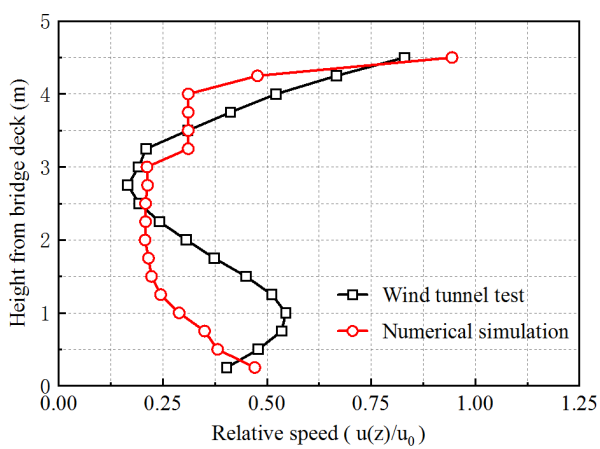

(b)

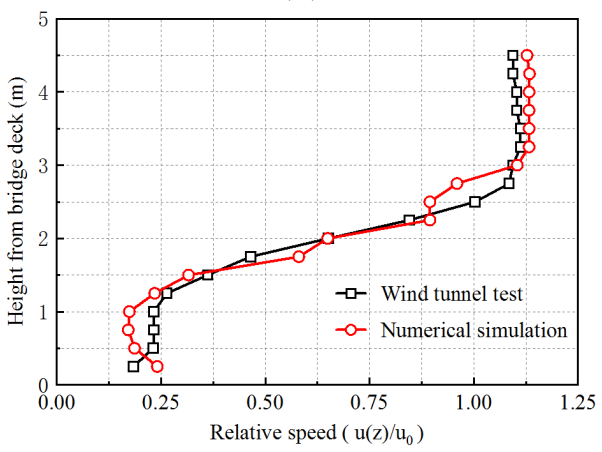

(d)

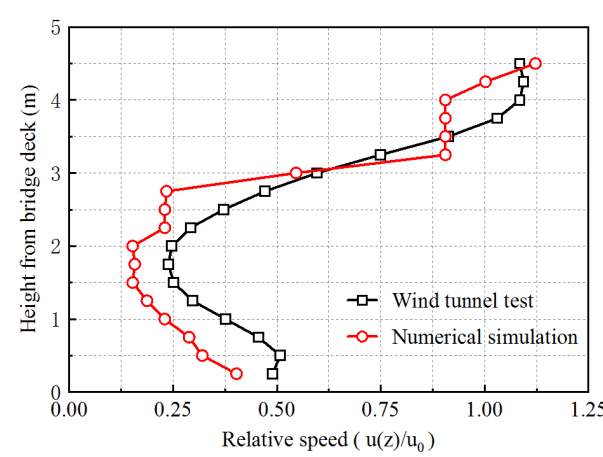

(c)

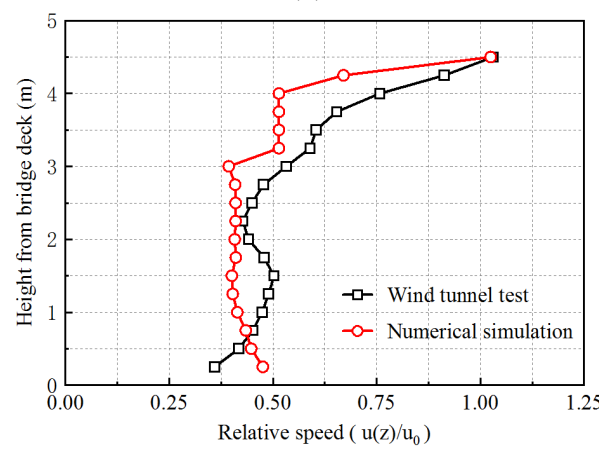

(e)

Figure 14. Comparison of relative wind speed values $\left(\mathrm{u}(\mathrm{z}) / \mathrm{u}_{0}\right)$ for different wind barriers in Lane 2 ((a) Scheme 1; (b) Scheme 2-1; (c) Scheme 2-2; (d) Scheme 2-3; (e) Scheme 3). 


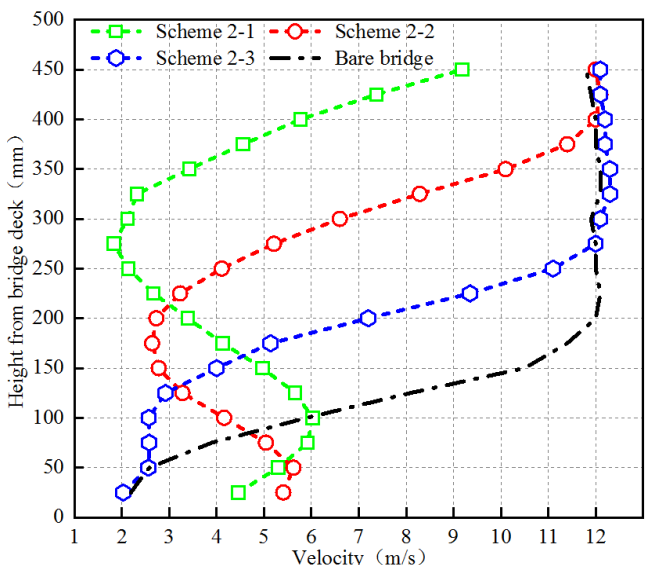

(a)

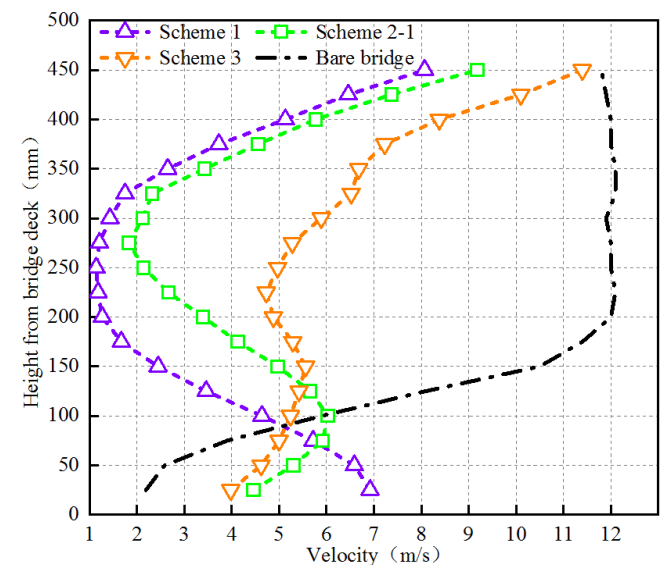

(b)

Figure 15. Effect of wind barrier on wind speed of a bridge deck ((a) Different height scheme; (b) Different porosity scheme).

The porosity of the barrier strip is a key parameter affecting the wind barrier performance, as shown in Figure 15b. The wind barrier scheme has poor performance in wind resistance within a height of $10 \mathrm{~cm}$ above the ground, and the wind speeds of most of the measurement points are larger than the incoming wind speed, which will lead to the lower part of the van wind pressure increasing and resulting in an adverse impact on the safety of driving; When the ground clearance is above $15 \mathrm{~m}$, the sheltering effect increases as the porosity decreases, and the improvement in the sheltering effect is more marked when the porosity decreases from $60 \%$ to $50 \%$ than when the porosity reduces from $50 \%$ to $40 \%$. The smaller the porosity is, the greater the effective sheltering height. There is a significant nonlinear relationship between the wind speed of the bridge deck and both the height and porosity of the wind barrier.

According to the speed test, the strip-type wind barrier has a significant effect on reducing the wind speed of the bridge in a specific height range, but it will induce an airflow acceleration zone near the ground. To evaluate the wind resistance effect of the strip-type wind barrier more objectively, the force measurement tests of the van under the different barrier schemes are carried out. The conditions of aerodynamic side force and lift force under different heights and porosities of the wind barrier are shown in Figure 16. The aerodynamic side force has significant regular changes with porosity and height, but the aerodynamic lift shows irregular changes. The reason for this situation is that the aerodynamic lift is more sensitive to the near-ground wind speed. However, the irregular changes in the near-ground wind speed of the bridge under different wind barrier schemes lead to irregular changes in aerodynamic lift, which is consistent with the numerical simulation results. Consequently, when the porosity is deterministic, the aerodynamic side force increases as the height of the barrier decreases. At a certain height, the aerodynamic side force increases with increasing porosity. The change in barrier height has a greater effect on the aerodynamic lift, mainly due to its influence on the wind speed near the ground on the windward side of the truck, while the change in porosity has a smaller effect on the aerodynamic lift. 


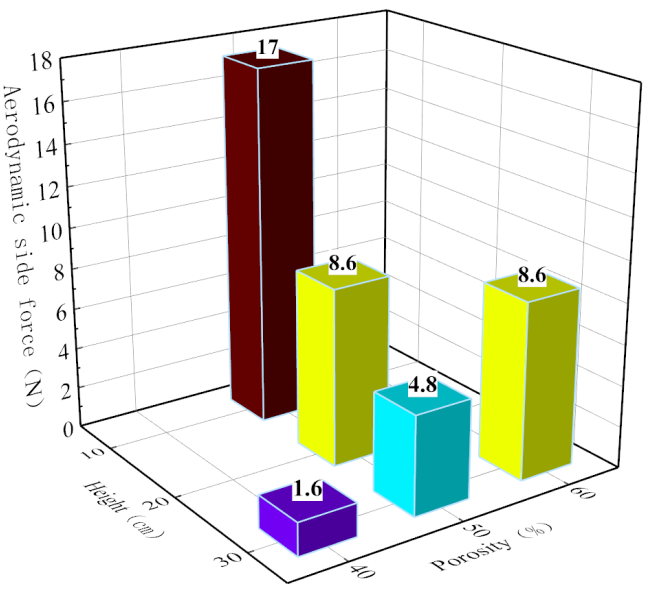

(a)

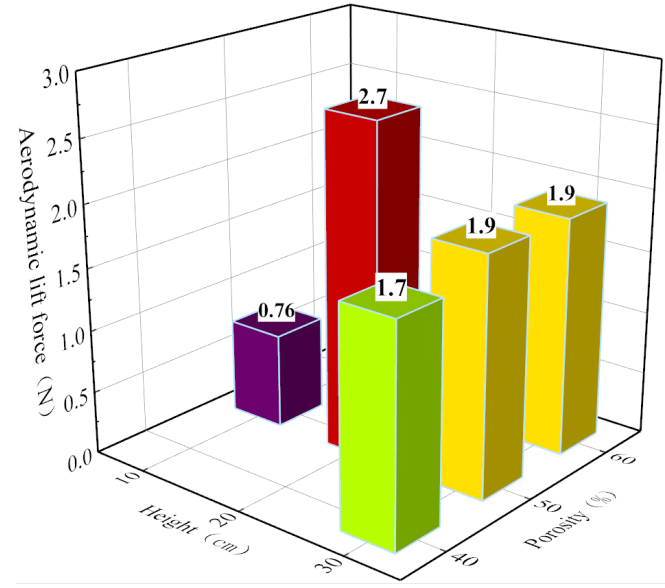

(b)

Figure 16. Effect of wind barrier on aerodynamic force ((a) Side forces; (b) Lift forces).

\section{Influence and Analysis of Wind Barrier on the Truck's Driving Stability}

In this paper, the straight-line driving stability of a van is analyzed by the unidirectional coupling method with a Trucksim dynamics analysis system. The truck parameters of the multi-body dynamics model are shown in Table 1.

Table 1. Main parameters of the vehicle dynamics for the van truck.

\begin{tabular}{ccc}
\hline Parameter & Unit & Value \\
\hline Width of the van truck $(w)$ & $\mathrm{mm}$ & 2400 \\
Height of the van trck $(h)$ & $\mathrm{mm}$ & 3900 \\
Length of the van truck $(l)$ & $\mathrm{mm}$ & 8500 \\
The distance from the center of mass to the front axis $\left(l_{f}\right)$ & $\mathrm{mm}$ & 2500 \\
The height from the center of mass to the ground $\left(h_{z}\right)$ & $\mathrm{mm}$ & 1620 \\
Stiffness of the front suspension $\left(K_{s f}\right)$ & $\mathrm{N} / \mathrm{m}$ & 250,000 \\
Damping of the front suspension $\left(C_{s f}\right)$ & $\mathrm{N} \cdot \mathrm{s} / \mathrm{m}$ & 15,000 \\
Stiffness of the rear suspension $\left(K_{s r}\right)$ & $\mathrm{N} / \mathrm{m}$ & 700,000 \\
Damping of the rear suspension $\left(C_{s r}\right)$ & $\mathrm{N} \cdot \mathrm{s} / \mathrm{m}$ & 30,000 \\
Roll moment of inertia for the van truck $\left(I_{x x}\right)$ & $\mathrm{kg} \cdot \mathrm{m}^{2}$ & 2283.9 \\
Pitch moment of inertia for the van truck $\left(I_{y y}\right)$ & $\mathrm{kg} \cdot \mathrm{m}^{2}$ & $35,402.8$ \\
Yawing moment of inertia for the van truck $\left(I_{z z}\right)$ & $\mathrm{kg} \cdot \mathrm{m}^{2}$ & $34,802.6$ \\
Unladen weight of the van truck $(\mathrm{G})$ & $\mathrm{kg}$ & 4455 \\
\hline
\end{tabular}

First, the aerodynamic forces of the van under different working conditions are obtained, and then the forces are loaded into the multi-body dynamics model to obtain its lateral motion response parameters under different working conditions, as shown in Figure 17. In consideration of the natural wind characteristics, a step gust model with a duration of $3 \mathrm{~s}$ is applied, which starts in $2 \mathrm{~s}$ and ends in $5 \mathrm{~s}$. The preview control driver model is introduced to be consistent with the actual driving conditions. By controlling the steering wheel angle, the driver system makes the lateral deviation between the vehicle position and the expected path track as zero as possible when the vehicle reaches the preview point ahead, and the preview time is set to $1.4 \mathrm{~s}$. Dry asphalt pavement is used in the simulation, and the adhesion coefficient is 0.85 . 

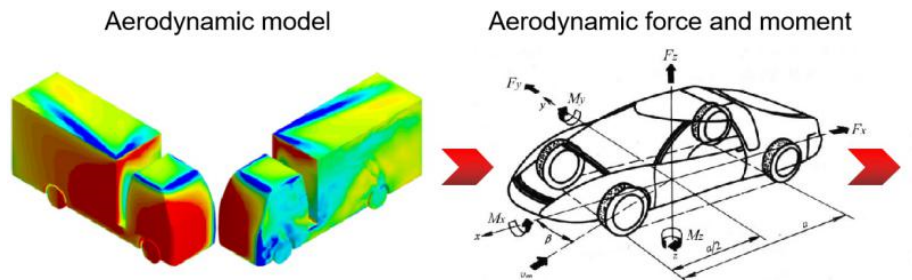

Multibody dynamics model

(a)

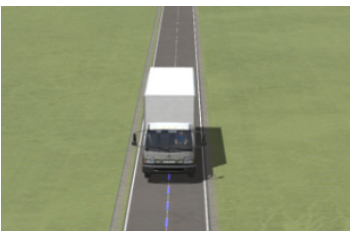

(b)

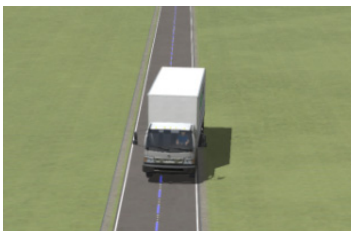

(c)

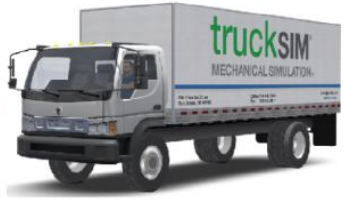

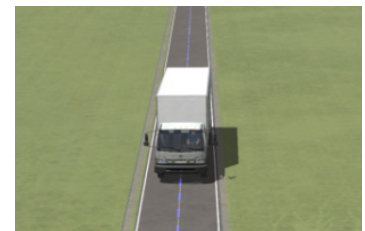

(d)

Figure 17. Calculation method of aerodynamic stability ((a) Analysis process of driving stability; (b) driving state without crosswind action; (c) driving state with crosswind action; (d) driving state with driver feedback control).

Figure 18 shows the lateral acceleration response curves for different operating conditions. The lateral wind acts in the second second and disappears in the fifth second, with a continuous action time of $3 \mathrm{~s}$. At the moment of disappearance of crosswind action, the lateral acceleration has sudden changes. It increases with the wind barrier porosity and decreases as the wind barrier height increases. During the change of porosity from $40 \%$ to $60 \%$, the peak lateral acceleration response increases from $0.084 \mathrm{~g}$ to $0.162 \mathrm{~g}$, the value of the three porosity schemes is reduced by $70.9 \%, 56.4 \%$, and $43.9 \%$ respectively, compared to the bare bridge condition $(0.289 \mathrm{~g})$. The peak lateral acceleration response increased from $0.126 \mathrm{~g}$ to $0.233 \mathrm{~g}$ during the height reduction from $3 \mathrm{~m}$ to $1 \mathrm{~m}$. The values of the three height schemes are reduced by $56.4 \%, 46.1 \%$, and $19.4 \%$, respectively, compared to the bare bridge condition $(0.289 \mathrm{~g})$.

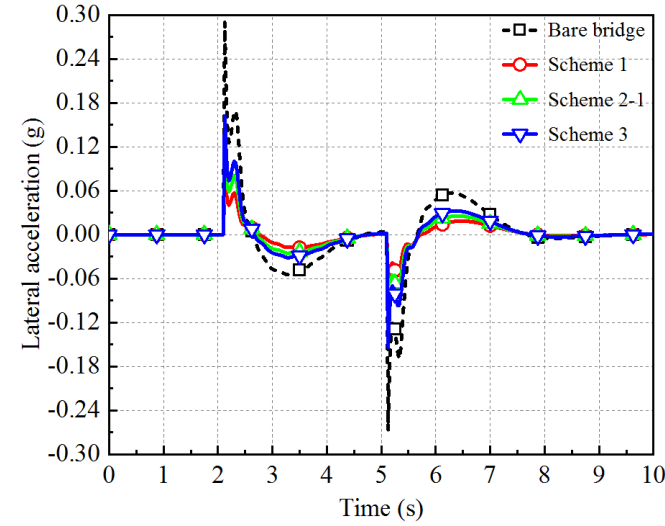

(a)

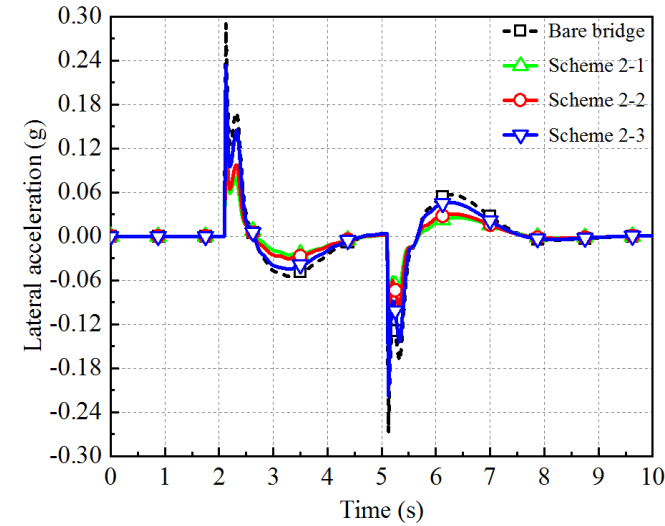

(b)

Figure 18. Lateral acceleration with different bridge wind barriers ((a) Different porosity scheme; (b) Different height scheme).

Figure 19 show the yaw velocity response curves under different working conditions. The van has yaw motion under the action of the yaw moment and the changing trend under different barrier structure parameter schemes is similar. The yaw velocity reaches to a maximum value approximately $1 \mathrm{~s}$ after lateral wind action, and the yaw velocity increases with increasing of porosity and increases with decreasing of wind barrier height. The peak yaw velocity increases from $0.557^{\circ} / \mathrm{s}$ to $0.937^{\circ} / \mathrm{s}$ when the porosity increases 
from $40 \%$ to $60 \%$. Compared to the bare bridge condition $\left(1.714^{\circ} / \mathrm{s}\right)$, the three porosity schemes reduce $67.5 \%, 56.1 \%$, and $45.3 \%$, respectively. As the height decreased from $3 \mathrm{~m}$ to $1 \mathrm{~m}$, the peak yaw velocity increases from $0.753^{\circ} / \mathrm{s}$ to $1.411^{\circ} / \mathrm{s}$. Compared to the bare bridge condition $\left(1.714^{\circ} / \mathrm{s}\right)$. the values of three height schemes decreased by $56.1 \%, 45.8 \%$, and $17.7 \%$, respectively.

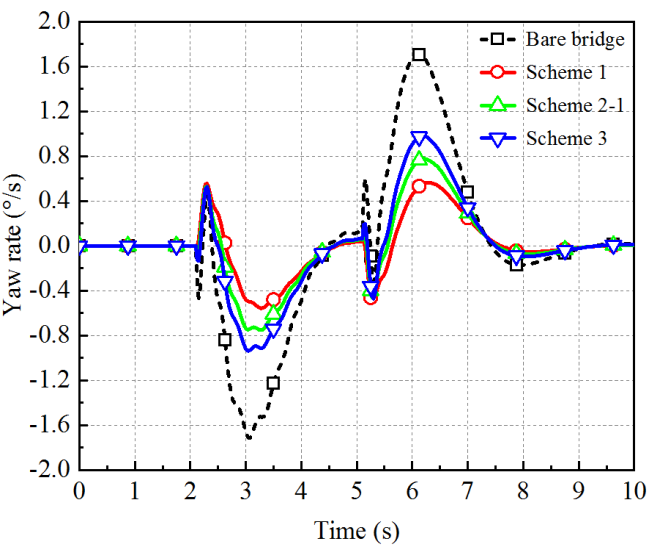

(a)

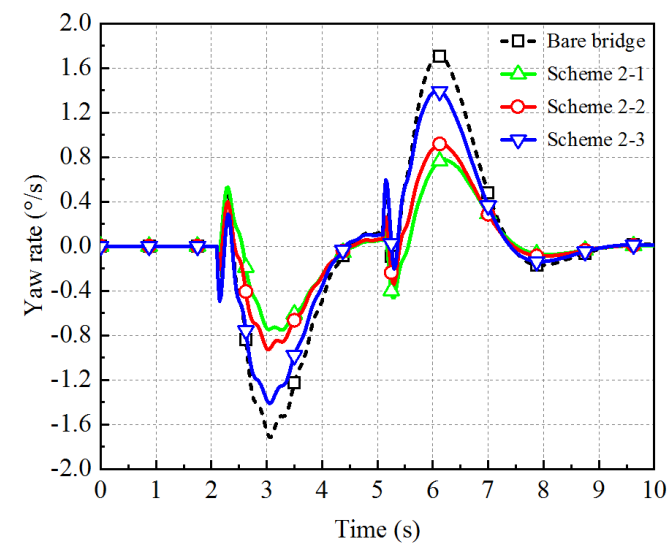

(b)

Figure 19. Yaw rate with different bridge wind barriers ((a) Different porosity scheme; (b) Different height scheme).

Under the crosswind action, the van has lateral and yaw movement along the crosswind direction, deviating from the predetermined straight-line driving trajectory. Then the lateral displacement reaches a maximum in the duration act of the crosswind approximately $2 \mathrm{~s}$ and will gradually return to the predetermined driving route after the driver operation, as shown in Figure 20. The lateral displacement increases with the porosity and increases as the height of the wind barrier decreases. As the porosity rate increases from $40 \%$ to $60 \%$, the peak lateral displacement increases from $0.226 \mathrm{~m}$ to $0.367 \mathrm{~m}$. Compared to the bare bridge condition $(0.598 \mathrm{~m})$, the three porosity rate schemes decrease by $62.2 \%, 50.5 \%$, and $38.6 \%$. As the height decreases from $3 \mathrm{~m}$ to $1 \mathrm{~m}$, the peak lateral displacement increases from $0.296 \mathrm{~m}$ to $0.476 \mathrm{~m}$ compared to the bare bridge condition (0.598), the values of the three height schemes decrease by $50.5 \%, 44.3 \%$, and $20.4 \%$.

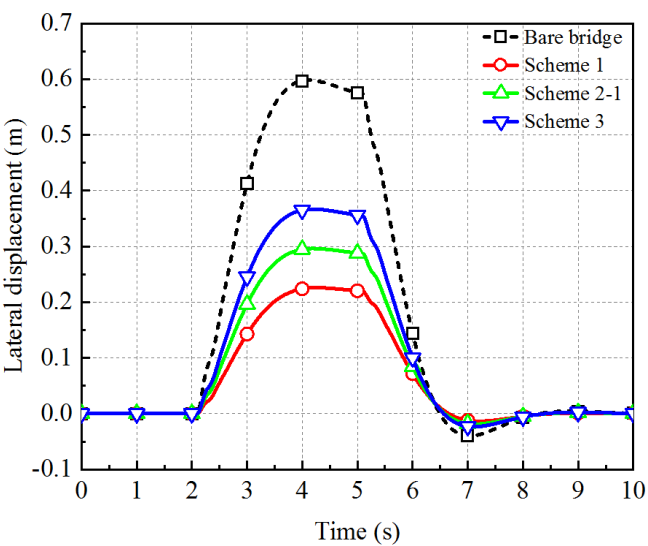

(a)

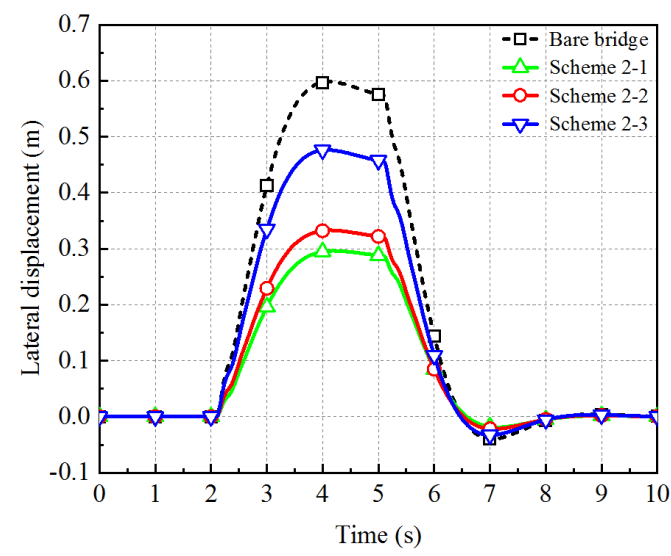

(b)

Figure 20. Lateral displacement with different bridge wind barriers ((a) Different porosity scheme; (b) Different height scheme).

In summary, the van will have lateral motion and yaw motion under the action of the lateral wind. The fluctuation of lateral acceleration and yaw velocity has a negative impact 
on the maneuvering stability, which will aggravate the driver's correction difficulty and be detrimental to driving safety. The setting of the wind barrier can effectively control the truck's lateral movement and yaw movement. The wind barrier with different structural parameters can greatly reduce the truck's peak lateral acceleration and yaw velocity response. The lateral displacement is smaller than the bare bridge working condition, which can improve the driving safety of trucks on the bridge. In addition, the shielding effect of the barrier height of $1 \mathrm{~m}$ plus the barrier of $50 \%$ porosity is sufficient to protect the truck at a height of $4 \mathrm{~m}$. For example, the three-lane single bridge in this paper has a lane width of $3.5 \mathrm{~m}$, and the van-body truck with a width of $2.4 \mathrm{~m}$ travels along the centerline of the lane. Then the distance between the van and lane edge is $0.55 \mathrm{~m}$, the van-body truck moves at a speed of $80 \mathrm{~km} / \mathrm{h}$ speed on the bridge under the $25 \mathrm{~m} / \mathrm{s}$ strong wind. Under such conditions, it is easy to drive into the adjacent lane and cause traffic accidents. However, after the installation of strip-type wind barriers with $50 \%$ porosity and a height of $1 \mathrm{~m}$ on both sides of the bridge, the lateral displacement of the truck will decrease from $0.598 \mathrm{~m}$ to $0.476 \mathrm{~m}$, which can meet the traffic safety needs.

\section{Discussion and Results}

In this paper, the analysis of the side wind stability of trucks on cross-sea bridges is carried out with numerical calculation and wind tunnel test methods. This study investigates the quantitative influence of the structural parameters of strip-type wind barriers on the aerodynamic characteristics and linear driving stability of trucks on bridges. The research results can provide a new method for analyzing wind-induced traffic safety and the design of bridges against wind under severe wind loads. The main conclusions are as follows:

(1) A quantitative evaluation method of bridge wind barriers is proposed based on the coupling method of vehicle aerodynamics and multi-body dynamics, which can comprehensively evaluate the influence of bridge wind barriers on the aerodynamic performance and crosswind stability of vehicles and provide a reference for the selection of wind barriers and the design of structural parameters. The method with quantitative analysis can obtain better porosity and height of the wind barriers, which can meet the requirements of wind-induced traffic safety on bridges and reduce the structural safety hazards of bridges caused by the retrofitting of wind barriers.

(2) The wind barrier height and porosity are the key parameters affecting the bridge deck wind speed and the effective shelter height. The average wind speed decreases with decreasing porosity, and the effective shelter height increases as the porosity decreases when the wind barrier height is determined; the average wind speed at the bridge deck decreases with increasing wind barrier height, and the effective shelter height increases with increasing wind barrier height for a given wind barrier porosity;

(3) The aerodynamic side force is sensitive to wind barrier porosity and height change. After the installation of wind barriers, the aerodynamic side force of the van-body truck decreases significantly. It decreases with the increase in wind barrier height and the decrease in wind barrier porosity; variations in the porosity and height of the wind barriers lead to irregularities in the wind speed near the bridge's ground and the aerodynamic lift of the van truck;

(4) The aerodynamic side force is a crucial parameter to determine the crosswind stability of the van truck. After adding the wind barrier, the straight-line driving stability of the van is significantly improved. The lateral acceleration, yaw velocity, and lateral displacement decrease with increasing height of the wind barrier, and with decreasing porosity of the wind barrier.

Author Contributions: Conceptualization, Z.Y.; methodology, Z.Y. and L.L.; software, Y.L. (Yufeng Liu) and D.X.; validation, L.L., X.L. and Y.L. (Yufeng Liu); project administration, Z.Y. and L.L.; writing manuscript, Z.Y., Y.L. (Yuehan Li) and D.X.; investigation, X.L.; data curation, L.L. and D.X. All authors have read and agreed to the published version of the manuscript. 
Funding: This research was funded by the Natural Science Foundation of Fujian Province (2020J01275), the Science and Technology Project of Fujian Province (2020H6022, 2021Y0045), the Transportation Science and Technology Project of Fujian Province $(202022,201903)$ and the Science and Technology Innovation Platform of Fujian Province (2016H2003).

Informed Consent Statement: Not applicable.

Data Availability Statement: All data presented in this study are available within the manuscript.

Acknowledgments: The authors would like to thank Fujian Provincial Department of Science and Technology and Fujian Provincial Department of Transportation for funding support, anonymous reviewers for their helpful comments, and Hengqing Lv for his assistance.

Conflicts of Interest: The authors declare no conflict of interest.

\section{References}

1. Zhu, L.D.; Li, L.; Xu, Y.L.; Zhu, Q. Wind tunnel investigations of aerodynamic coefficients of road vehicles on bridge deck. J. Fluids Struct. 2012, 30, 35-50. [CrossRef]

2. Zhang, Q.; Su, C.; Zhou, Y.; Zhang, C.; Ding, J.; Wang, Y. Numerical investigaion on handing stability of a heavy tractor semi-trailer under crosswind. Appl. Sci. 2020, 10, 3672. [CrossRef]

3. Elvik, R.; Sagberg, F.; Langeland, P.A. An Analysis of Factors Influencing Accidents on Road Bridges in Norway. Accid. Anal. Prev. 2019, 129, 1-6. [CrossRef] [PubMed]

4. Dorigatti, F.; Sterling, M.; Rocchi, D.; Belloli, M.; Quinn, A.D.; Baker, C.J.; Ozkan, E. Wind tunnel measurements of crosswind loads on high sided vehicles over long span bridges. J. Wind Eng. Ind. Aerodyn. 2012, 107, 214-224. [CrossRef]

5. Yuan, Z.; Gu, Z.; Wang, Y.; Huang, X. Numerical investigation for the influence of the car underbody on aerodynamic force and flow structure evolution in crosswind. Adv. Mech. Eng. 2018, 10, 1687814018797506. [CrossRef]

6. Kozmar, H.; Procino, L.; Borsani, A.; Bartoli, G. Sheltering efficiency of wind barriers on bridges. J. Wind. Eng. Ind. Aerodyn. 2012, 107, 274-284. [CrossRef]

7. He, X.; Xue, F.; Zou, Y.; Chen, S.; Han, Y.; Du, B.; Xu, X.; Ma, B. Wind tunnel tests on the aerodynamic characteristics of vehicles on highway bridges. Adv. Struct. Eng. 2020, 23, 2882-2897. [CrossRef]

8. Zhan, K.; Lin, X.; Yang, Y.; Lian, J.; Hou, H.; Liu, G.; Hu, L.; Lin, L. Experimental research on wind resistance of bridge wind barrier under different structural parameters. J. Fuzhou Univ. 2021, 49, 217-224.

9. Chen, N.; Li, Y.; Wang, B.; Su, Y.; Xiang, H. Effects of wind barrier on the safety of vehicles driven on bridges. J. Wind. Eng. Ind. Aerodyn. 2015, 143, 113-127. [CrossRef]

10. Kozmar, H.; Procino, L.; Borsani, A.; Bartoli, G. Optimizing height and porosity of roadway wind barriers for viaducts and bridges. Eng. Struct. 2014, 81, 49-61. [CrossRef]

11. Dong, Z.; Luo, W.; Qian, G.; Lu, P.; Wang, H. A wind tunnel simulation of the turbulence fields behind upright porous wind fences. J. Arid. Environ. 2010, 74, 193-207. [CrossRef]

12. Wang, L.; Chen, X.; Chen, H. Research on wind barrier of canyon bridge-tunnel junction based on wind characteristics. Adv. Struct. Eng. 2021, 24, 870-883. [CrossRef]

13. Wang, Y.; Guo, W.; Xia, H.; Zhang, N.; Zhang, T. Wind tunnel test of tri-component coefficients for a train-bridge system considering wind barrier effect. J. Vib. Shock 2018, 37, 88-94.

14. Zhen, X.; Su, Y.; Xiang, H.; Li, Y. Influence of wind barrier on aerodynamic characteristics of vehicles on rail-cum-road bridge. Railw. Eng. 2018, 58, 25-30.

15. Zhang, J.; Zhang, M.; Li, Y.; Huang, X.; Zheng, Z. Aerodynamics of high-sided vehicles on truss girder considering sheltering effect by wind tunnel tests. Balt. J. Road Bridge Eng. 2020, 15, 66-88. [CrossRef]

16. Xiang, H.; Li, Y.; Chen, S.; Hou, G. Wind loads of moving vehicle on bridge with solid wind barrier. Eng. Struct. 2018, 156, 188-196. [CrossRef]

17. Xue, F.; Han, Y.; Zou, Y.; He, X.; Chen, S. Effects of wind-barrier parameters on dynamic responses of wind-road vehicle-bridge system. J. Wind. Eng. Ind. Aerodyn. 2020, 206, 104367. [CrossRef]

18. Nakashima, T.; Tsubokura, M.; Vazquez, M.; Owen, H.; Doi, Y. Coupled analysis of unsteady aerodynamics and vehicle motion of a road vehicle in windy conditions. Comput. Fluids 2013, 80, 1-9. [CrossRef]

19. Chu, C.R.; Chang, C.Y.; Huang, C.J.; Wu, T.R.; Wang, C.Y.; Liu, M.Y. Windbreak protection for road vehicles against crosswind. J. Wind. Eng. Ind. Aerodyn. 2013, 116, 61-69. [CrossRef] 